\title{
INTERFACE DA ABORDAGEM CTS COM A DIVERSIDADE DE RELAÇÕES SOCIAIS NAS AULAS DE BIOLOGIA
}

\section{CTS APPROACH INTERFACE TO DIVERSITY OF SOCIAL RELATIONS IN BIOLOGY CLASSES}

\author{
André Luiz Rodrigues dos Santos Cunha ${ }^{1}$ \\ Ana Cristina Pimentel Carneiro de Almeida ${ }^{2}$
}

\section{RESUMO}

Este texto trata sobre a prática docente no enfoque Ciência, Tecnologia e Sociedade (CTS) e a diversidade de relações sociais em aulas de biologia. Tem como objetivo identificar na fala docente a aproximação das relações sociais com o ensino de ciências em sua ação pedagógica, baseada na proposta CTS. A metodologia desse estudo foi concebida segundo os pressupostos da pesquisa narrativa de Clandinin e Connelly, em que o professor sujeito da pesquisa expõe em seu discurso, a percepção de como ele privilegia em sua prática pedagógica a conduta solidária, o respeito às diferenças sociais e aos ritmos de aprendizagem. Como o referencial teórico, trazemos autores como Krasilchik, Marandino, Santos, Mortimer, Pinheiro, Silveira e Bazzo. Os resultados do trabalho apontam para a possível contribuição do enfoque CTS para realizar uma reflexão sobre a necessidade de incluir na formação docente, em destaque no ensino de ciências, a discussão de práticas que conduzam para um novo olhar sobre as relações sociais na perspectiva da formação cidadã.

Palavras-chave: CTS - Ensino de Ciências - Relações Sociais.

\section{ABSTRACT}

This text deals about the teaching practice in CTS approach and diversity of social relationships in biology classes. Aims to identify in the speak of an teacher the approximation of social relations with science education in their pedagogical action based on the CTS focus. The methodology of this study was designed according to the assumptions of the research narrative Clandinin and Connelly, in which the research subject teacher expose in his speech, the perception of how it focuses on the conduct of their practice solidarity, respect of for differences social and aprendizagem.For the theoretical referecial, we bring authors as Krasilchik, Marandino, Santos, Mortimer, Pine, and Bazzo Silveira. The results of the study point to a possible approximation of the CTS approach to the social relations. So brought valuable contributions to the debate on the need to include in teacher 
education, highlighted in science teaching, discussion of practices that lead to new vision into the social relations in the perspective of the citizen formation.

Keywords: CTS - Science Education - Social Relations.

\section{INTRODUÇÃO: PARA COMEÇO DE CONVERSA}

A escola como uma representação da sociedade é um espaço onde é notória a observação de que a diversidade se faz presente, assim como, às relações sociais que se estabelecem no decorrer da história de vida de cada um de seus integrantes. Segundo Clandinin e Connelly (2011) nos encontramos nesse entremeio e isso implica dizer que pairamos no meio de um conjunto de histórias de vida dos diversos sujeitos que se relacionam. Então podemos dizer que o pensamento narrativo trabalha na exploração das fronteiras históricas pessoais e alcança uma forma de reflexão nesta relação de temporalidade.

Escreva-se um texto de pesquisa que atenda tanto as questões pessoais quanto sociais, olhando-se interna e externamente, abordando questões temporais olhando não apenas para o evento, mas para o seu passado e futuro (CLANDININ; CONNELLY, 2011, p.86).

Esse trabalho retrata o professor em um olhar introspectivo, refletindo sobre as interações sociais que se estabelecem diariamente com seus alunos. Essa pesquisa predispõe-se a fazer uma reflexão de cunho pedagógico de um educador de Biologia sobre sua prática de ensino. Concordamos com Larossa (2008, p. 38) quando afirma que "em termos gerais o passado transmite significado, o presente transmite valores e o futuro transmite intenção" caracterizando o contexto espacial e temporal onde se concretiza o cenário de sala de aula, onde a trama se desenvolve.

Então, como é a percepção de um professor de Biologia neste contexto? Não é intenção deste questionamento, generalizar esta percepção, mas voltar à atenção para as expectativas de um docente considerando as demandas 
sistematizadas. Se, por um lado há a preocupação com o conteúdo programático, com as cobranças da sociedade, dos alunos, dos familiares, da escola, por outro, há a importância de trabalhar a formação de valores e as relações sociais que emergem internamente e externamente na sala aula, tão propagadas no enfoque CTS. Investigar como um professor de ciências lida paralelamente com essas questões através da análise de sua narrativa é o objetivo desse artigo.

O professor, de modo geral, ao estruturar o seu planejamento de ensino busca oportunizar a aprendizagem de seus alunos, levando em consideração a relação entre os objetivos a serem alcançados, os conteúdos a serem abordados e as estratégias de ensino que poderão ser utilizadas. Porém, essa tríade pode ser insuficiente para garantir o sucesso na formação do aluno, uma vez que mesmo planejando os objetivos em torno dos conteúdos e das estratégias pedagógicas, por vezes o professor acaba esquecendo-se de considerar as singularidades dos alunos envolvidos no processo de ensino e aprendizagem. Neste sentido,

Em relação aos objetivos, embora, muitas vezes, eles estejam muito bem explicitados e tecnicamente bem formulados, ficam comprometidos no desenrolar da situação pedagógica, na medida em que giram em torno dos conteúdos apenas, pois os sujeitos do processo nem sempre são devidamente considerados. (TACCA, 2006, p.46).

Assim sendo, percebe-se a necessidade de um planejamento de ensino que além de pensar em conteúdos programáticos, objetivos educacionais, procedimentos metodológicos, critérios avaliativos, procure também, abarcar as interações envolvendo tanto alunos quanto o próprio professor. Essas relações do espaço pedagógico da sala de aula envolvem "concepções, crenças, histórias de vida, e outros aspectos emergentes no processo relacional, que geram as escolhas e opções a serem necessariamente feitas" (TACCA, 2006, p. 46-47). Por exemplo, as interações sociais e culturais quando colocadas à margem da ação docente, principalmente no ensino de ciências exatas e naturais (matemática, física, química e biologia). 
Refletir sobre estratégias de ensino na ação docente vai além de concebê-las como recursos aplicados para desenvolver conteúdos programáticos de um currículo a ser cumprido, mas também visualizá-las, como:

recursos relacionais que orientam o professor na criação de canais dialógicos tendo em vista adentrar o pensamento do aluno, suas emoções, conhecendo suas interligações impostas pela unidade cognição-afeto (TACCA, 2006, p.48).

É esse canal dialógico que o professor precisa estabelecer para trabalhar as questões tanto cognitivas quanto afetivas, que direcionem para 0 desenvolvimento de uma conscientização das diferenças culturais, socioeconômicas, étnico-raciais, religiosas, entre outras. Isso implica ensinar o aluno a aprender na diferença e com as diferenças, pois que cada um é singular dentre a pluralidade de uma escola, de uma família e da sociedade como um todo.

\section{CONVERSANDO SOBRE O ENSINO DE CIÊNCIAS E A ABORDAGEM CTS}

O ensino de Ciências, entre os anos de 1950-1960, enfatizava o método científico, priorizando a aprendizagem de conteúdos conceituais e a participação dos estudantes em atividades experimentais de laboratório. Ao adentrar na década de 70, ocorre o surgimento do movimento Ciência, Tecnologia e Sociedade (CTS) e a valorização da relação entre conhecimento científico, desenvolvimento tecnológico e vida social. Nos anos 80 se inicia uma forte influência do construtivismo nas práticas pedagógicas, e o movimento CTS ganha força com uma perspectiva de trazer mudanças no ensino de ciências, objetivando uma melhor preparação dos alunos para atuarem ativamente na sociedade. Ao chegar à década de 90, a centralidade da discussão sobre as interações entre ensino de Ciências e formação para a cidadania mostram-se como ressonâncias do contexto sociopolítico da sociedade brasileira, desse momento histórico.

Atualmente, na perspectiva do enfoque CTS discussões são feitas sobre a importância da contribuição do ensino de ciências para o desenvolvimento 
do exercício da cidadania. A partir disso pode-se afirmar que a reforma do ensino de Ciências, no Brasil, ao longo desse meio século, foi motivada pelas transformações ocorridas nas esferas, social, política e econômica, nos âmbitos nacional e internacional.

A legislação educacional brasileira (LDB e os PCNs) prevê a importância das relações sociais e étnico-raciais nos processos educativos, com a finalidade de formação para a cidadania independentemente da área de conhecimento que o professor atua, ou seja, a formação cidadã inclui responsabilidade aos professores de ciências de desenvolverem valores em seus alunos que são incompatíveis com injustiças ou qualquer forma de discriminação cultural, religiosa ou étnico-racial. Isso pode ser percebido na promulgação da Lei 10.639/03 que instituiu a obrigatoriedade do ensino de História e Cultura AfroBrasileira e Africana no sistema de educação escolar brasileiro em todos os seus níveis.

Essa lei não afirma que se deve criar uma disciplina sobre esse tema ou que é uma temática, por exemplo, exclusivamente da disciplina história. Todas as disciplinas podem contribuir significativamente em seus conteúdos programáticos trabalhando para a formação desses valores, e o movimento CTS que, apesar de não ter surgido no âmbito educativo, influenciou de modo incisivo, notadamente, a área da Educação científica e Tecnológica. Essa discussão perpassa fundamentalmente pelas concepções de ciência e tecnologia construídas durante a história social da humanidade (PINHEIRO; SILVEIRA; BAZZO, 2007).

Nesta linha, Santos e Mortimer (2001) comentam sobre a quebra paradigmática do mito cientificista, em que a concepção de neutralidade científica e a crença de que a ciência é capaz de resolver as grandes questões éticas, sociais e políticas da humanidade já não é tão aceita como era antes.

O movimento CTS surgiu, então, em contraposição ao pressuposto cientificista, que valoriza a ciência por si mesmo, depositando uma crença cega em seus resultados positivos. A ciência era vista como uma atividade neutra de domínio exclusivo de um grupo de especialistas, que 
trabalhava desinteressadamente e com autonomia na busca de um conhecimento universal, cujas conseqüências ou usos inadequados não eram de sua responsabilidade. A crítica a tais concepções, responsabilidades e cumplicidades dos cientistas, enfocando a ciência e tecnologia como processos sociais (SANTOS; MORTIMER, 2001, p. 95).

Assim, o movimento CTS surge como uma proposta de educação para a cidadania, baseada em abordagens e práticas de ensino capazes de integrar o conhecimento científico com as realidades socioculturais, econômicas e políticas globais e locais.

A implantação do movimento CTS, com a intenção de propiciar um ensino com caráter interdisciplinar e contextualizado, mostra-se condizente com o trabalho estabelecido na legislação educacional, que traz como prerrogativa a formação e atualização de um novo perfil de educador.

\section{O CAMINHO TRILHADO NA PESQUISA}

Para este trabalho apresentamos como metodologia empregada a investigação narrativa, durante o ano de 2013, com um professor de ciências sobre a sua prática pedagógica em relação a temas voltados para a abordagem CTS. Conforme Connelly e Clandinin (2011, p.11) "a principal razão para o uso de narrativa em investigação educacional é que nós seres humanos somos organismos contadores de histórias, organismos que, individualmente e socialmente vivemos vidas relatadas", por isso, segundo esses autores concebese que os estudos da narrativa descrevem como os seres humanos experimentam o mundo.

Os instrumentos utilizados para coletar as narrativas desse docente foram uma entrevista, um questionário e uma tarefa de complemento de frases, sendo este último inspirado em Gonzáles Rey (2005). Esses instrumentos possibilitaram a reflexão tanto do pesquisador quanto do professor pesquisador sobre a ação pedagógica em um ensino de ciências mais humanista sem desconsiderar a sua especificidade técnica. A seguir, apresentamos a 
interpretação sobre as narrativas do docente pesquisado a luz dos instrumentos utilizados para este fim.

\section{SOBRE AS DIVERSIDADES DE RELAÇÕES SOCIAIS NO ENSINO DE CIÊNCIAS: COM A PALAVRA, O PROFESSOR GUTO}

O professor investigado, neste estudo será chamado de Guto. Trabalha na rede estadual de ensino na cidade de Belém e no município de Concórdia do Pará. O professor Guto, atualmente é aluno de mestrado do Programa de PósGraduação em Educação em Ciências e Matemáticas do Instituto de Educação Matemática e Científica (IEMCI), na Universidade Federal do Pará (UFPA). Nesse programa, ele faz parte de um grupo de estudos de Ciência-TecnologiaSociedade-Ambiente (GECTSA). Em relação a sua participação nesse grupo de estudos ele se descreve da seguinte forma:

"Vejo-me como um participante do grupo, alguém que se esforça para divulgar e conquistar adeptos para essa "bandeira". Ainda um pouco antes de minha entrada no mestrado já costurávamos a possibilidade de instituir esse grupo, pensando no quanto poderia ser interessante 0 envolvimento de mais pessoas para que essa perspectiva pudesse alcançar outros professores e consequentemente as escolas".

Sobre essa questão de fazer uma retrospectiva introspectiva, compreendemos como Cunha (1997), que quando uma pessoa relata os fatos vividos por ela mesma, percebe-se que reconstrói a trajetória percorrida dando-lhe 
novos significados. Assim, a narrativa não é a verdade literal dos fatos, mas antes, é a representação que o sujeito faz dele e dessa forma, pode ser transformadora da própria realidade.

O professor entrevistado se diz atento às polêmicas que as questões sociais podem trazer para o espaço da sala de aula, como se pode observar em seu discurso: "sempre que percebo situações de preconceitos, falta de respeito e intolerância em relação à cor da pele, religião e sexualidade, intervenho, converso com a turma no sentido de reflexão desta situação". Essa é a postura que se espera de qualquer cidadão independente da sua profissão. Para isso, o professor busca em sua memória experiências de sua ação docente, de como podemos atentar para o fato e relata em seguida:

"Realizei trabalhos pontuais na escola que trabalho no município de Concórdia do Pará, este município apresenta um grande quantidade de pessoas negras devido ao fator histórico de remanescentes de Quilombolas. Assim as salas de aula apresentavam muitos alunos negros. No dia da consciência negra, foi realizado um evento na escola sobre essa questão. Como atividade, tive como projeto a oficina de beleza negra: que realizou tipos de corte de cabelo para negros, maquiagens específicas para negros e vestimentas com cores para negro. Reforçando a cultura afrodescendente, realizada por uma amiga que aceitou $O$ convite, representante do CEDENPA- Centro de estudo e defesa do negro no estado do Pará foi quem proferiu a oficina".

As iniciativas citadas pelo professor Guto são importantes, porém não podem ser concebidas como atividades esporádicas, pontuais, e ou eventuais. Essa postura de discussão das diferenças não pode ser uma ação sazonal, onde 
fica vinculada a datas específicas. Ela deve ser trabalhada por qualquer disciplina em todo o decorrer do processo educativo.

Ao ser perguntado sobre as principais vantagens da aplicação de uma abordagem CTS no ensino de ciências, obtivemos como resposta:

"Hoje eu não vejo o CTS no sentido de uma aplicação, mas como perspectiva que possa permear a sala de aula num processo que possa levar professores e estudantes e até a comunidade escolar, dependendo do alcance, a um processo educacional mais crítico. E é nesse sentido da criticidade que aspectos relacionados com a Ciência, Tecnologia e Sociedade têm seu ponto forte. Pois nesse sentido, é possível a construção de um ensino voltado a formação para a cidadania."

Sobre isso Krasilchik e Marandino (2007) argumentam que a formação de cidadãos precisa de algumas competências como: ser capaz de expressar seus julgamentos de valor; diferenciar entre decisões pessoais (de âmbito individual) e decisões coletivas (de âmbito público); reconhecer e aceitar direitos, deveres e oportunidades em uma sociedade pluralista, entre outros. Pode-se observar que o professor Guto, não vê o enfoque CTS como algo que simplesmente pode ser utilizado no ensino de ciências, mas sim um ensino de ciências pautada na perspectiva CTS para poder atingir as competências citadas por Krasilchik e Marandino para a formação cidadã.

Em seguida the foi perguntado por que ainda é tão difícil aplicar o enfoque CTS no ensino médio?

O que o professor Guto traz nessas narrativas são supostos culpados para o problema que a educação de uma forma geral enfrenta: a formação docente, as condições estruturais dos estabelecimentos de ensino, as pressões 
por um ensino tradicional visando a entrada na universidade e a precariedade dos livros didático. Ele começa da seguinte forma:

"Primeiro por que os professores precisam compreender que a abordagem CTS não deve se configurar como uma aplicação. Precisa haver uma mudança paradigmática no professor, ou a quebra do pensamento eminentemente positivista de ensino... o obstáculo não é o professor em si, mas a sua formação... a formação continuada de professores segundo essa vertente se faz necessária"

Observa-se que a questão da formação foi atribuída em primeiro lugar o que Krasilchik e Marandino (2007) já destacam como ponto importante no repensar da educação. Posterior a isso: "as tensões escolares internas e externas para cumprimento de conteúdo programático ao estilo vestibulescos...".

O professor destaca as pressões sofridas pelos professores e na fala a seguir ela chama atenção para uma suposta postura comodistas de docentes e discentes quando expressa que "professores e alunos já estão habituados com o formato de ensino que exploram quase que exclusivamente a memorização de conteúdos." Os professores podem até estar habituados com esse modelo de ensino, mas não podem estar conformados e com isso ficar acomodados nesse modelo de educação como reprodução de conteúdos.

As tensões e ou pressões a que o professor Guto se refere também corresponde a um problema levantado por Krasilchik e Marandino (2007) que comentam que essa situação advém do receio que muitos professores têm de discutir temas que envolvam valores devido ao medo de repressão social ou política, divergências com as famílias e preconceitos que acabam levando à manutenção de suas aulas em um patamar seguro, ou seja, dentro de uma zona de conforto, na qual as discussões sobre diferentes pontos de vistas são evitadas.

O professor Guto complementa: "em terceiro as questões estruturais", mas percebe ser este um problema geral da educação e, ainda, comenta sobre a 
escassez e ineficiência dos livros didáticos "pois ainda que na tentativa de estabelecer discretas ações segundo essa perspectiva...poucos alcançam de fato o professor e consequentemente a sala de aula."

Essas considerações demonstram um quadro desafiador para 0 professor que busca trabalhar com essa iniciativa, pois não teve uma formação adequada, tem que conviver cotidianamente com as pressões sobre o seu trabalho; se depara algumas vezes com questões estruturais deficitárias e não dispõem de um material didático, como livro, para subsidiar o seu trabalho. É por isso que o professor Guto não concebe a abordagem CTS como uma aplicação, mas, sim como uma mudança paradigmática, uma metamorfose nas relações professor-aluno.

Para ampliar nossa discussão, foi feita ao professor a seguinte pergunta: Como a abordagem CTS contribui para trabalhar a diversidade de relações sociais?

"Não teria uma "receita de bolo". Acredito que por meio de trabalhos com conteúdo axiológicos relacionados a situações do cotidiano dos educandos compreendendo os diferentes valores que os grupos sociais apresentam, propor forma de como conhecer os diferentes. Como CTS seria importante observar as tomadas de decisão pelos educandos em relação à temática problematizadora"

O ensino de Ciências enquanto campo de estudos busca compreender a aprendizagem de conhecimentos originados no campo das Ciências Naturais, e seus possíveis impactos, também em outros espaços educativos (KRASILCHIK; MARANDINO, 2007). Para isso o professor não concebe um manual de regras que possa seguir para alcançar esses objetivos. Por isso torna-se importante buscar respostas às questões relativas ao papel social do ensino de Ciências, 
frente às diversidades estabelecidas nas relações étnico-raciais, ainda observadas como dispares na nossa sociedade.

Certo consenso entre os professores e pesquisadores da área da educação em ciências que o ensino dessa área tem como uma das suas principais funções a formação do cidadão cientificamente alfabetizado, capaz de não só identificar o vocabulário da ciência, mas também de compreender conceitos e utiliza-lós para enfrentar desafios e refletir sobre seu cotidiano (KRASILCHIK; MARANDINO, 2007, p. 19).

\section{Então, a visão de aprendizado que o professor Guto compartilha} aproxima-se da concepção de Moreira (1997, p. 43)

Aprender, não é somente conhecer algo inédito, é principalmente reprocessar amplificadamente o conhecimento prévio através da interação como novo; "para ser significativa deve ser substantiva e não arbitrária, ao invés de nominalista ou meramente representacional.

Ao ser indagado sobre como trabalha a diversidade em suas aulas de ciências, ele relata que "O respeito é o principal apelo, compreender o diferente.... Sempre que possível solicito a tolerância com o outro que esta próximo mesmo que não concorde com seu modo de vida". Essa postura está de acordo com as Diretrizes Curriculares Nacionais para a educação, pois:

[...] o ensino das diferentes áreas de conhecimentos e, além disso, sensíveis e capazes de direcionar positivamente as relações entre pessoas de diferentes pertencimento étnico-racial, no sentido do respeito e da correção de posturas, atitudes, palavras preconceituosas. Daí a necessidade de se insistir e investir para que os professores, além de sólida formação na área específica de atuação, recebam formação que os capacite não só a compreender a importância das questões relacionadas à diversidade étnico-racial, mas a lidar positivamente com elas e, sobretudo criar estratégias pedagógicas que possam auxiliar a reeducá-las, para o ensino das diferentes áreas de conhecimentos e, além disso, sensíveis e capazes de direcionar positivamente as relações entre pessoas de diferente pertencimento étnico-racial, no sentido do respeito e da correção de posturas, atitudes, palavras preconceituosas. Daí a necessidade de se insistir e investir para que os professores, além de sólida formação na área específica de atuação, recebam formação que os capacite não só a compreender a importância das questões relacionadas à diversidade étnico-racial, mas a lidar positivamente com elas e, sobretudo criar estratégias pedagógicas que possam auxiliar a reeducá-las. (BRASIL, 2004, p. 17). 
Percebemos que para trabalhar as relações sociais é necessário envolver as diversas ciências para formação de um cidadão mais consciente, reflexivo e crítico para uma sociedade mais igualitária e menos preconceituosa.

Em outro encontro pedimos ao professor para fazer uma tarefa de complemento de frases. As quatro primeiras frases foram: 1- CTS, 2- Ciência, 3Tecnologia e 4-Sociedade. Estas frases estimularam a produção das seguintes narrativas:

A abordagem CTS para o professor Guto é "uma alternativa no ensino de ciências", enquanto que o acrônimo formado pelas letras CTS que correspondem a Ciência, Tecnologia e Sociedade foram separadamente expressadas pelas seguintes falas do professor:

"Ciência: Acredito que atualmente como professor é importante elucidar aos educandos que a ciência poder se tornar benéfica ou maléfica a sociedade. Acredito também que é importante reforçar as estratégias educacionais, ou seja, as potencialidades das ciências em beneficio para humanidade, tanto para quem for fazer ciências, ciências hard, como também para quem utiliza a ciência como um meio. Tecnologia: Corresponde ao produto desse conhecimento que dependendo dos interesses por trás envolvidos podem trazer benefícios ou malefícios. Algo importante para ser frisado e que essa tecnologia esteja ao alcance de todos independente de questões de econômicas, religiosas, de gênero e ou étnico-racias. Sociedade: precisa saber lidar com as diferenças e um passo importante para isso é a harmonia entre a ciência e a tecnologia diante da diversidade de sujeitos integrantes." 
A visão que o professor Guto tem da tríade ciência, tecnologia e sociedade, está de acordo com a explicação de SANTOS e MORTIMER (2001, p. 96):

\begin{abstract}
A ciência não é uma atividade neutra e o seu desenvolvimento está diretamente imbricado com os aspectos sociais, políticos, econômicos, culturais e ambientais. Portanto a atividade científica não diz respeito exclusivamente aos cientistas e possui fortes implicações para a sociedade. Sendo assim, ela precisa ter um controle social que, em uma perspectiva democrática, implica em envolver uma parcela cada vez maior da população nas tomadas de decisão sobre Ciência e Tecnologia.
\end{abstract}

Ele percebe a importância de conscientizar de que não existe uma linearidade entre desenvolvimento cientifico, progresso, tecnologia e bem estar social. O que a ciência produz poder ter diversos outros interesses que não estejam entre os que gostaríamos de ter como cidadãos.

Para o professor cada aluno é diferente, ou seja, "cada aluno tem potencialidades e dificuldades diferenciadas e isso deve ser respeitado por quem trabalha na educação". Por isso, ele é enfático em dizer que educar nas diferenças é "desafiador!". Além disso, ele manifesta um claro desejo diante da frase: Minha prática pedagógica diante da multiplicidade de relações sociais. Seu complemento foi sincero e claro quando humildemente revela que "gostaria de aumentar!". Isso também é percebido no complemento da frase: Minha disciplina lida com as diferenças que ele fez simplesmente com "adaptando!".

O desafio de trabalhar a questão das diferenças sociais na disciplina biologia talvez seja oriundo dos obstáculos citados anteriormente pelo professor, mas que ele mostra vontade de melhorar esse ensino adaptando-se aos novos tempos e questões sociais.

Essas lacunas podem ser fruto de uma formação deficitária, extremamente positivista durante o seu curso de licenciatura, observada quando ele diz que as questões sociais na sua formação foram "Bem poucas!". Dessa forma como já foi dito anteriormente, pode-se afirma que Guto olha para o 
passado buscando significado nas coisas que fez para representar os valores que ele considera importante e que tem intenção de alcançá-los no futuro.

O professor Guto comenta sobre a rigidez do conhecimento científico e a partir disso aproveita para comentar sobre a sua práxis educativa como uma maneira de ultrapassar essa ciência rigidamente desumanizada:

"Como professor de Ciências Naturais e Biologia, percebo as ciências consideradas hard, devido ao rigor científico e pela sua historicidade e epistemologia. Minha ação docente tem preocupação com os aspectos sociais e humanísticos por meio das ciências naturais pode promover, no sentido do melhoramento do bem estar social em respeito a diferentes culturas."

Ao relacionar cidadania e ensino de ciências, o professor continua mostrando convicção ao falar em uma formação educacional visando à cidadania, pois:

"esse é um dos principais objetivos da educação científica a formação cidadã. Demonstrando por meio de debates em sala de aula aspectos controversos das ciências, que as verdades cientificas são mutáveis, atende a uma determinada época da História, ensinado com temas sociocientíficos a sobre a realidade do educando. Dessa forma o ensino de ciências estará contribuindo para tomada de decisão utilizando os conhecimentos científicos, para melhoria de sua qualidade de vida e do meio social em vive".

O professor Guto, mostra sinais de sentir-se desafiado com essa concepção de ensino, pois ao falar sobre formação cidadã ele levanta questões 
sócio, políticas e econômicas que são pertinentes para a reflexão sobre 0 momento histórico que a educação está passando.

"Acredito que seja o desafio deste século, pois possibilitar a formação cidadã não é tão simples. Porém, proporcionar a formação cidadã para o bem estar social, formar um indivíduo que participe democraticamente e de forma crítica das problemáticas sociais, diante de uma estrutura capitalista e desenvolvimentista é desafiador".

Ter bem claro os objetivos do enfoque CTS, representa para Guto fator primordial para a produção de conhecimentos no ensino de Biologia. O que segue a linha de raciocino de Santos e Mortimer (2001) em que alegam que o principal objetivo do currículo CTS é o letramento científico e tecnológico para que os alunos possam atuar como cidadãos, tomando decisões e agindo com responsabilidade social. Essa abordagem deve produzir transformações levando 0 ensino a formar pessoas críticas na sociedade.

O professor Guto concebe sua sala de aula como "um estabelecimento de debates em ciências", pois possui como "um ideal" uma educação em ciências de qualidade para todos e assim procura "transformar e ser transformador, sempre". Isso porque esse educador acredita que o objetivo da educação é "O bem estar da sociedade!", para isso considera importante desenvolver no aluno valores sociais "para ser tornar um cidadão crítico-reflexivo". Essa produção narrativa do professor mostra que o papel da escola é fazer a transposição do acadêmico para a realidade da vida. $O$ ensino de ciências pode facilitar em muito essa perspectiva.

Não basta fornecer informações atualizadas sobre questões de ciências e tecnologia para que os alunos de fato se engajem ativamente em questões sociais. Como também não é suficiente ensinar ao aluno passos para a tomada de decisão. Se desejamos preparar os alunos para participar ativamente de decisões da sociedade, precisamos ir além do ensino conceitual, em direção a uma educação voltada para a ação social 
responsável, em que haja preocupação com a formação de atitudes e valores (SANTOS E MORTIMER, 2001, p. 107).

Segundo o relatório Delors, 1997 feito pela UNESCO, intitulado "Educação: um tesouro a descobrir", a educação se baseia em quatro pilares que são: "aprender a conhecer", "aprender a fazer", "aprender a viver juntos" e "aprender a ser". O terceiro pilar citado é bem claro na importância de relações étnico-raciais que se configuram no respeito pela diversidade e igualdade de direitos, pois ele:

envolve a realização de projetos comuns por grupos de composição variada, compreensão e a aceitação de diferenças e de semelhanças que permitem reconhecer a unicidade da espécie humana, cuja sobrevivência depende da cooperação para superar conflitos e resolver problemas locais, regionais e universais (KRASILCHIK, MARANDINO, 2007, p. 4142).

Essas intenções que o professor Guto busca, demonstra em suas narrativas a preocupação com um ensino de ciências voltado para as questões sociais e com isso revelando um significado para o aluno. Isso evidencia que quando o professor pensa de forma coletiva está preocupado com o futuro desse aluno que ele está ajudando a formar. Isso se contrasta com um trabalho excessivamente individualista preocupado apenas em cumprir metas de conteúdo onde a atenção docente está centrada apenas no momento presente.

\section{FINALIZANDO ESTA CONVERSA}

O ensino baseado na abordagem CTS necessita, não apenas, da oferta de propostas curriculares multidisciplinares, interdisciplinares e transdisciplinares orientando novas estratégias de ensino de ciências inter-relacionadas com a tecnologia e a sociedade, mas um investimento constante na formação acadêmica, na formação continuada de professores, na pesquisa e preparação de recursos didáticos e estruturais. 
Essa conclusão ficou evidenciada nas narrativas do professor Guto que tenta superar as dificuldades de uma formação ineficiente no que diz respeito a questões sociais a partir de uma prática educativa que promova um desenvolvimento de postura mais crítica e reflexiva em seus alunos. Por isso ele percebe que ao adotar a abordagem CTS em sua práxis docente, também estará trabalhando questões sobre multiculturalismo, diversidade e relações étnicoraciais, isso porque a contribuição da ciência e da tecnologia para as discussões sociais não podem se restringir a apenas uma parcela da sociedade.

Essa investigação narrativa realizada com o professor contribuiu para a reflexão dos pesquisadores de como a narrativa representa tanto o fenômeno que se investiga quanto o método de investigação e concordando com Connelly e Clandinin (2011, p. 48) que afirmam que a "experiência é uma palavra chave, educação e estudo de educação são formas de experiências onde a narrativa seria o melhor modo de representar e entender a experiência".

Essa é a concepção de educação que precisa ser formada em professores de diversas áreas. Independente da disciplina o valor de sociedade será medido pelo valor que seus integrantes dão as relações que estabelecem entre si. Concluímos que iniciativas como as do professor pesquisado nesse estudo demonstram que o ensino de ciências possuem importantes contribuições para a discussão e reflexão de temas sociais.

A articulação entre cidadania, ensino de ciências, relações sociais e culturais torna-se importante para superação de estereótipos e preconceitos, valorizando com isso a diversidade e o respeito étnico-racial no estudo das ciências naturais. Então, além do respeito aos direitos universais, ressaltamos a importância da formação de docentes comprometida com a educação de cidadãos críticos, reflexivos e atuantes na discussão de questões de cunho social. 


\section{REFERÊNCIAS}

BRASIL. Ministério da Educação. Secretaria de Educação Continuada, Alfabetização e Diversidade. Diretrizes Curriculares Nacionais para Educação das Relações Étnico- Raciais. Brasília: MEC, 2004.

CLANDININ, Jean; CONNELLY, Michael. Pesquisa Narrativa: experiências e historias em pesquisa qualitativa. EDUFU, 2011

CUNHA, Maria Isabel da. Conta-me Agora!: As narrativas como alternativas pedagógicas na pesquisa e no ensino. Rev. Fac. Educ. (online). 1997, vol.23, n.12 ISSN 0102-2555. Disponível: http://dx.doi.org/10.1590/S010225551997000100010. Acesso em: 07.10.2013.

GONZÁLEZ REY, F. L. Pesquisa qualitativa e subjetividade: os processos de construção da informação. SILVA, M. A. F. (Trad.). São Paulo: Pioneira Thomson Learning. 2005.

KRASILCHIK, M.; MARANDINO, M. Ensino de Ciências e cidadania. SP: Moderna, 2007.

LARROSA, Jorge. Déjame que te cuente. ensayos sobre narrativas y educación. Ciudad Autónoma de Buenos Ares:Laertes 2008. Editoria Laertes, 2008.

MOREIRA, M. A. Modelos mentais. Porto Alegre, UFRS, 1997

PINHEIRO, N. A. M; SILVEIRA, R. M. C. F; BAZZO, W. A. Ciência, tecnologia e sociedade: a relevância do enfoque CTS para o contexto do ensino médio. Ciência \& Educação, Bauru, v. 13, n. 1, mês, 2007, p. 71-84.

SANTOS, Wildson Luiz P.; MORTIMER, Eduardo F. Tomada de Decisão para ação social responsável no ensino de ciências. Ciência \& Educação, Bauru, v.7, n.1, p.95-111, 2001.

TACCA, M. C. Estratégias pedagógicas: conceituação e desdobramentos com foco nas relações professor-aluno. Em: M. C. V. R. Tacca (org.) Aprendizagem e Trabalho Pedagógico. Campinas, SP: Alínea, 2006, pp. 45-68.

\footnotetext{
1alrscunha@ig.com.br, titulação de Especialização, trabalha atualmente como professor efetivo da Universidade Federal do Pará, lotado na Escola de Aplicação (EAUFPA) e está regularmente matriculado no curso de mestrado do Programa de Pós-Graduação em Educação em Ciências e Matemáticas (PPGECM) do Instituto de Educação Matemática e Científica (IEMCI) da Universidade Federal do Pará (UFPA)
} 
2 anacrispimentel@gmail.com, titulação de Doutorado, trabalha atualmente como professora do Instituto de Educação Matemática e Científica (IEMCI) da Universidade Federal do Pará (UFPA) e professora colaboradora do Programa de Pós-Graduação em Educação em Ciências e Matemáticas (PPGECM) da UFPA.

RECEBIDO EM: novembro/2013

APROVADO EM: dezembro/2013 